\title{
O DESAFIO DAS ESTATÍSTICAS DO TERCEIRO SETOR
}

Felícia Reicher Madeira

Miriam Ribeiro Biancardi

\begin{abstract}
Resumo: O presente texto traz as experiências que a Fundação Seade vem desenvolvendo a fim de contribuir para a quantificação e qualificação de informações estatísticas relacionadas ao Terceiro Setor. Palavras-chave: produção de dados estatísticos; terceiro setor; cadastro georreferenciado.

Abstract: This text presents those experiments being carried out by Fundação Seade aimed at contributing to the quantification and the qualification of statistical information related to the Third Sector, Non-Governmental Organizations.

Key words: data production; third sector; geo-referenced registry.
\end{abstract}

$\mathrm{O}$ Terceiro Setor é considerado hoje, ao lado do Estado e do setor privado, um importante sustentáculo da sociedade moderna. Muito embora as organizações da sociedade civil de caráter público existam desde há muito tempo, estas, curiosamente, não eram reconhecidas como pertencentes a um setor específico da economia. Somente a partir do início da década de 90 é que estas organizações passaram a ser conceituadas e mensuradas como um setor específico da economia, revelando sua importância tanto social como econômica. A explicação para tal omissão são várias, mas uma dificuldade importante está na metodologia do cálculo das Contas Nacionais, conceito macroeconômico que, dividindo as atividades humanas em agrícolas, industriais e de serviços, incluía as organizações da sociedade civil nesta última classificação sem, no entanto, destacar suas características próprias. Neste conceito econômico, pertencem ao item educação, por exemplo, tanto as organizações privadas como as públicas e as do Terceiro Setor. Ao conceituar o Terceiro Setor como o conjunto das organizações constituídas por agentes privados, mas com finalidade de produzir bens e serviços públicos, foi possível dar-lhe uma identidade distinta dos outros setores, permitindo sua visualização.
A verdade é que a questão do Terceiro Setor vem ganhando muita importância e destaque no contexto do debate acadêmico e político atual sobre o papel da sociedade civil. De fato, embora a reflexão sobre a sociedade civil tenha sido sempre corrente nestes debates, nos últimos anos esta reflexão revestiu-se de novas e precisas especificações conceituais, passando a ser reconhecida agora sob a rubrica de "a nova sociedade civil". Esta concepção inova basicamente ao referir-se à emergência de novos atores sociais, imbuídos de qualificações e que são considerados indispensáveis para a implementação de um desenvolvimento sustentável.

Como eco desta reflexão internacional, processo semelhante vem acontecendo no Brasil. As entidades da sociedade civil sem fins lucrativos dedicadas a ações sociais têm longa existência no país, entretanto, nas últimas décadas, têm se multiplicado com rapidez e alterado suas características no que diz respeito tanto à sua constituição como à sua ação e aumentando a sua visibilidade. Cada vez mais elas vêm se consolidando em um formato que as distancia da tradicional dedicação à filantropia e à caridade, para focalizar sua atuação no âmbito de um espaço mais politizado da sociedade or- 
ganizada e na busca de ampliação e racionalização da sua ação social. De fato, o crescimento do associativismo e de participação da população brasileira vem amadurecendo em simultâneo à idéia de fragmentar a sociedade em espaços de ação política que não mais se confundem com as formas de representação, mas que podem formar redes que se conectam solidariamente e potencializam as ações de proteção sociais. Essas novas formas de organização da sociedade têm sido recebidas e, mais do que isto, muito estimuladas, devido também a reflexões que vêm se reforçando na área de economia institucional e que apontam para o fato de que o associativismo é um forte indutor do desenvolvimento econômico/social.

Certamente é este cenário, ou, mais que isto, esta crença que faz com que estas novas entidades ou novas associações com serviços dedicados ao público venham se tornando atores cada vez mais presentes tanto nas ações mais gerais de desenvolvimento social (sobretudo na área de geração de renda e alívio da pobreza), quanto nas ações mobilizadoras de interlocutores mais qualificados nos fóruns de debates e discussões de políticas mais gerais, adquirindo por este motivo crescente visibilidade junto à mídia e ao público em geral.

A discussão internacional, com forte impacto sobre a agenda nacional, tem sido um reforço constante na questão da importância da co-responsabilidade social e de complementaridade entre as ações efetivadas pelos diversos setores e atores que atuam no campo social. Existe a compreensão, quase um consenso, de que a interação de ações e agentes que implementam políticas públicas propicia uma troca de conhecimento sobre as distintas experiências, o que acaba por proporcionar maior racionalidade, criatividade, qualidade e eficácia às ações desenvolvidas em todas as instâncias envolvidas, sobretudo por evitar as superposições de recursos e competências.

A crescente aposta na importância da co-responsabilidade, por sua vez, tem impulsionado a constituição da figura das parcerias, que implica reconhecer, entender e encontrar as formas de relacionamento entre agentes com lógicas distintas de atuação em torno de objetivos comuns, sem perda de identidade e desvio de suas missões institucionais. Na verdade, as significativas diferenças entre as lógicas de governo, de mercado e da sociedade civil organizada são entendidas como complementares e cada vez mais necessárias e produtivas nas tarefas de formulação e implementação de uma estratégia de desenvolvimento sustentável.
Pois bem, apesar do consenso em torno da relevância do Terceiro Setor no desenvolvimento social, são crescentes os desafios enfrentados pelos três setores para garantir a eficiência esperada neste novo arranjo. Estes desafios se traduzem por necessidades de redefinição de suas funções tradicionais, novos formatos de organização interna, adequação de conformações jurídicas, melhorias na capacitação de recursos humanos e na gestão institucional, em busca da eficiência, transparência, avaliação e qualidade de resultados e reconhecimento e legitimidade junto à sociedade.

Várias ações têm sido desenvolvidas no sentido de enfrentar estes desafios, sobretudo para qualificar melhor as entidades e torná-las capazes de captar recursos, elaborar e gerir os projetos, desenvolver metodologias de avaliação de resultados qualitativos e financeiros, etc. Entretanto, persiste ainda um conjunto de dúvidas e incertezas sobre este modelo de atuação: como escolher a entidade mais adequada para a realização de determinada parceria? A presença ou ausência de uma parceria com entidades comunitárias faz diferença? Se faz, quanto e de que tipo? Quais são e como mensurar e reproduzir os efeitos benéficos?

Para começar a encaminhar respostas a estas e a outras questões, é absolutamente consensual a idéia da importância e da urgência de organizar tanto um bom cadastro que atue com instrumento gerencial, como o desenvolvimento de uma pesquisa que qualifique e quantifique melhor o que vem sendo genericamente chamado de Terceiro Setor. Ocorre que, talvez, o maior desafio seja mesmo construir este cadastro.

O objetivo central deste texto é relatar três experiências da Fundação Seade relacionadas ao tema Terceiro Setor, explicitando as dificuldades, as limitações e as formas encontradas para enfrentar e/ou contornar as dificuldades:

- Cadastro das Entidades da Sociedade Civil da Região Leste do Município de São Paulo, que serviu como subsídio para o Serviço de Apoio às Micro e Pequenas Empresas - Sebrae implementar o projeto Integração Leste;

- Censo/Cadastro Georreferenciado de Entidades Sociais que atuam na área de cultura do Estado de São Paulo, que subsidiou o projeto Fábrica de Cultura em Áreas de Violência Juvenil, desenvolvido em parceria com o Banco Interamericano de Desenvolvimento (BID);

- Guia do Terceiro Setor, que está em fase de desenvolvimento, em parceria com a Fundação Mário Covas e Unicamp. As duas experiências anteriores oferecem pistas decisivas para o aperfeiçoamento deste projeto. 


\section{DEMANDAS QUE CHEGAM À FUNDAÇÃO SEADE}

Há algum tempo a Fundação Seade vem se qualificando para enfrentar, de forma competente, os desafios colocados para gerar, administrar e analisar um Cadastro de Entidades da Sociedade Civil Sem Fins Lucrativos, mais conhecidas como Terceiro Setor. Entende-se como Primeiro Setor aquele no qual a origem e a destinação dos recursos são públicas, isto é, correspondem às ações do Estado. Já o Segundo Setor refere-se ao capital privado, sendo a aplicação dos recursos revertida em benefício próprio. A atuação do Terceiro Setor ocorre na esfera pública nãoestatal, formada a partir de iniciativas privadas, voluntárias, sem fins lucrativos, e no sentido do bem comum.

Por se tratar de tarefa importante, demandada insistentemente por diferentes setores da sociedade, a Fundação Seade decidiu enfrentar este desafio, mesmo tendo presente as enormes dificuldades de levar a cabo tal atividade. Como órgão estatal responsável pela produção e disseminação de estatísticas para a sociedade em geral, a Fundação Seade está atenta às novas e crescentes demandas de informação colocadas pela agenda social mais atualizada, contribuindo para a transparência das ações de interesse público e social. Neste sentido, a instituição está ciente da importância deste produto para todos aqueles que necessitam de instrumentos de gestão para programas sociais e que atuam notadamente nos campos de planejamento, implementação e avaliação de políticas públicas.

A situação vivenciada hoje, de enorme lacuna de informações sistematizadas e organizadas do Terceiro Setor, decorre de três fatores: inexistência de um cadastro qualificado, já que os disponíveis foram idealizados para outras finalidades, são de difícil acesso e restringem-se, muitas vezes, a áreas de atuação específicas, além de raramente atualizados; os cadastros existentes quase nunca contêm dados que permitam qualificar adequadamente este setor; e, muito especificamente, as dificuldades para se conceituar o que é, afinal, o Terceiro Setor, uma vez que a denominação abriga uma grande variedade de instituições da sociedade civil com objetivos e estratégias distintas, cujos elementos de identidade correspondem à ausência de fins lucrativos e à promoção de interesses públicos. Nesse universo, incluem-se instituições filantrópicas, entidades profissionais, associações religiosas e de bairros, fundações, etc.

A intenção é gerar e disponibilizar na Internet um conjunto de informações que contribuirá fortemente para tor- nar mais fácil e eficiente o esforço de responsabilidade social que vem ganhando força no Brasil e, de modo especial, em São Paulo. A idéia é trazer à tona e disseminar informações sobre a atuação das entidades do Terceiro Setor e seu papel social, tais como: tipo de ações desenvolvidas; população atendida; história das parcerias; etc. Seria interessante também dar um tratamento especial aos aspectos econômicos relativos a receitas, despesas, fontes de financiamento, características dos seus colaboradores, bem como remuneração e jornada de trabalho dos funcionários. Finalmente, é importante tentar coletar e organizar as informações de modo a se tornarem minimamente comparáveis com os levantamentos internacionais.

\section{RELATO DAS EXPERIÊNCIAS}

\section{Cadastro das Entidades da Sociedade Civil da Região Leste de São Paulo}

O Programa de Apoio ao Desenvolvimento Metropolitano - Prodem - Integração Leste, concebido pelo Sebrae$\mathrm{SP}$, tinha como objetivo central a promoção de ações integradas de políticas voltadas para o desenvolvimento socioeconômico sustentável do grande e problemático aglomerado urbano que é a região Leste do Município de São Paulo. Em sua concepção, o Prodem apostava - em consonância com o conceito que predomina hoje: o poder da "nova sociedade civil" - que a melhor forma de implementar um projeto desta natureza seria através da formação de parcerias com agentes locais da sociedade civil. Ou seja, considerava-se que a integração das micros e pequenas empresas com outras formas de organizações da sociedade civil - cooperativas, empresas de participação, empresas de autogestão, associações, entidades de representação, ONGs, instituições de ensino, etc. - seria de vital importância para a economia local e para a construção de novos espaços sociais de geração de ocupação e renda de forma sustentável. Assumida essa postura conceitual, uma das ações prioritárias passou a ser a elaboração de um Cadastro das Entidades da Sociedade Civil Sem Fins Lucrativos desta área do Município de São Paulo.

Na verdade, tal demanda vinda do Sebrae, para o desenvolvimento do projeto Integração Leste, repetia uma solicitação constante e insistente, que chegava ao Seade, de órgãos públicos e privados que lidam com implementação de ações na área genericamente conhecida como desenvolvimento social. 
Diante desta constante demanda, a Fundação Seade aceitou a tarefa proposta pelo Sebrae de cadastrar todas as Entidades da Sociedade Civil Sem Fins Lucrativos da Zona Leste do Município de São Paulo, buscando levantar tanto dados puramente cadastrais como algumas indicações sobre a atuação das mesmas no ano de 2000: objetivos, âmbito de atuação, número de funcionários ou prestadores de serviços, número de voluntários, fontes de recursos, atividades principais, beneficiários, etc. Considerou-se importante também, para o bom andamento do projeto, que o cadastro de endereços pudesse contar com o recurso de georreferenciamento e que, além disso, os mesmos fossem plotados sobre uma base digitalizada de setores censitários, o que possibilitaria agregar importantes informações demográficas e socioeconômicas ao cadastro. Organizado e apresentado nesta forma, ou seja, somando a visualização geográfica do conjunto de entidades que atua em uma determinada região a informações sociodemográficas disponíveis para os setores censitários, o cadastro seria uma ferramenta poderosa para se chegar de forma direta e pontual à entidade desejada, bem como ao público-alvo, tornando muito mais eficientes e transparentes tanto as ações quanto o processo de escolha das entidades.

$\mathrm{O}$ primeiro problema que se colocou para a nossa equipe foi exatamente responder à questão: o que é Terceiro Setor? Após uma consulta bibliográfica nacional e internacional, discutindo inclusive a pesquisa desenvolvida pelo pessoal do Centro de Estudos do Terceiro Setor - CETS/ FGV e aplicada em Jaboticabal, tomou-se a primeira decisão: em face da fragilidade dos estudos teóricos encontrados e da diversidade de situações nacionais apontadas, a investigação seria estendida a todas as entidades sem fins lucrativos (exceto cartórios e condomínios), de modo a identificar, em toda sua complexidade, a situação encontrada no país.

O cadastro inicialmente utilizado foi uma combinação dos cadastros IBGE-97 e Rais MTE-98, selecionando-se as entidades sem fins lucrativos e também cooperativas e entidades com natureza jurídica pública atuando em ações sociais, para averiguar se pertenciam ou não ao Terceiro Setor. Aí também se apresentou outra dificuldade, que era como separá-las segundo sua organização jurídica.

A idéia inicial era contatar, por telefone, as entidades localizadas pelos cadastros. Entretanto, esta proposta foi inviabilizada dada a mudança dos prefixos dos números de telefones que acontecia, exatamente naquele momento, em todo o Estado de São Paulo. Além disso, os pri- meiros telefonemas mostraram que os responsáveis pelas entidades tinham enorme interesse em nos contatar pessoalmente para relatar com maior precisão a complexidade de sua ação.

Decidiu-se, então, realizar uma pesquisa por meio de visitas às entidades, o que mostrou ser de grande valia para começar a entender melhor este complexo universo. Entre março e junho de 2001, pesquisadores treinados pela Fundação Seade realizaram visitas aos locais de funcionamento das entidades arroladas, procedendo ao levantamento dos dados cadastrais e demais informações já relacionadas.

O primeiro exercício de georreferenciamento do cadastro obtido via comparação/compatibilização dos cadastros IBGE e Rais mostrou a existência de inesperados vazios, exatamente em áreas habitadas pelas populações de mais baixa renda, que deveriam ser o alvo das ações do Sebrae. Ocorre que, empiricamente, era do conhecimento do Sebrae que, naquela área, havia um número expressivo de associações em funcionamento. Para investigar o porquê da ocorrência desses vazios, foram tomadas duas decisões: coletar cadastros de diferentes entidades que realizavam parcerias com entidades na RMSP - fundações, associações, secretarias, etc. -; e realizar uma busca de endereços individuais através das consultas ao Cadastro Nacional de Pessoa Jurídica, da Secretaria da Receita Federal. Retiradas as duplicidades, o cadastro preexistente foi ampliado em cerca de $25 \%$ (em torno de 1.100 novas entidades foram encontradas, somando-se a um cadastro original de cerca de 4.000 entidades).

O levantamento foi a campo com um Cadastro Base de 5.047 entidades. Deste total, cerca de $26,2 \%$ das entrevistas não foram realizadas por diversos motivos, como exposto na Tabela 1. Entre estes, destaca-se o problema relativo à atualidade do cadastro, comum em levantamentos desta natureza, que foi responsável por cerca de $18 \%$ dos questionários não respondidos. O produto final é constituído por 3.501 Entidades da Sociedade Civil Sem Fins Lucrativos da Zona Leste do Município de São Paulo, sendo que 3.341 contam com informações integrais e 160 somente com os dados cadastrais.

As entidades sem fins lucrativos cadastradas, que estavam ativas na Zona Leste, em 2000, totalizam 3.388 e foram distribuídas segundo sua natureza jurídica (Tabela 2). As Associações representam a maioria das entidades sem fins lucrativos pesquisadas na Zona Leste (49,5\%), seguidas pelas Instituições Religiosas e/ou entidades Confessionais $(31,7 \%)$. As formas consideradas mais 
TABELA 1

Distribuição das Entidades da Sociedade Civil sem Fins Lucrativos, segundo Levantamento da Pesquisa

Zona Leste do Município de São Paulo - 2000

\begin{tabular}{lcc}
\hline Levantamento da Pesquisa & $\begin{array}{c}\text { Números } \\
\text { Absolutos }\end{array}$ & $\%$ \\
\hline Cadastro Original & $\mathbf{5 . 0 4 7}$ & 100,0 \\
Entrevistas Realizadas Completas & 3.341 & 66,2 \\
Entrevistas Realizadas só a Parte Cadastral & 160 & 3,3 \\
Entrevistas Não Realizadas & 1.321 & 26,2 \\
$\quad$ Fechada & 607 & 12,0 \\
$\quad$ Mudança para Local Desconhecido da Zona Leste & 175 & 3,5 \\
$\quad$ Duplicidade no Cadastro & 169 & 3,3 \\
$\quad$ Mudança para Local Fora da Zona Leste & 112 & 2,2 \\
$\quad$ Recusa & 136 & 2,7 \\
$\quad$ Sem Informação & 122 & 2,4 \\
Entidades Excluídas Posteriormente (1) & 225 & 4,5 \\
& & \\
\hline
\end{tabular}

Fonte: Sebrae/Fundação Seade. Cadastro das entidades da sociedade civil sem fins lucrativos da Zona Leste do Município de São Paulo.

(1) Entidades privadas com fins lucrativos; telemínios, escolas e pessoas físicas.

(2) Não estão incluidas no Cadastro Original.

\section{TABELA 2}

Distribuição das Entidades da Sociedade Civil sem Fins Lucrativos Ativas, segundo Natureza Jurídica

Zona Leste do Município de São Paulo - 2000

\begin{tabular}{|c|c|c|}
\hline Natureza Jurídica & $\begin{array}{l}\text { Números } \\
\text { Absolutos }\end{array}$ & $\%$ \\
\hline Total Geral & 3.388 & 100,0 \\
\hline Associações & 1.676 & 49,5 \\
\hline Associação sem Fins Lucrativos & 1.603 & 47,3 \\
\hline Organização Não-Governamental - ONG & 64 & 1,2 \\
\hline \multicolumn{3}{|l|}{ Organização da Sociedade Civil de } \\
\hline Interesse Público - Oscip & 9 & 1,9 \\
\hline Fundação ou Instituto & 41 & 1,2 \\
\hline Igrejas - Instituição Religiosa / Entidade Confessional & 1.073 & 31,7 \\
\hline Associação de Pais e Mestres & 522 & 15,4 \\
\hline Outros & 76 & 2,2 \\
\hline Cooperativa & 6 & 0,2 \\
\hline Entidade Sindical de Trabalhadores & 39 & 1,2 \\
\hline Sociedade de Advogados & 3 & 0,2 \\
\hline \multicolumn{3}{|l|}{ Órgão Público dos Poderes Executivo, } \\
\hline Legislativo ou Judiciário & 1 & 0,0 \\
\hline Outra Natureza & 23 & 0,7 \\
\hline Entidade Sindical Patronal & 4 & 0,1 \\
\hline
\end{tabular}

Fonte: Sebrae/Fundação Seade. Cadastro das entidades da sociedade civil sem fins lucrativos da Zona Leste do Município de São Paulo. modernas de organização, ONGs e Oscips, correspondem a cerca de $2 \%$ do universo pesquisado. Ainda de maneira expressiva aparecem as Associações de Pais e Mestres $(15,4 \%)$.

De maneira geral, observou-se que grande parte das entidades atua há longo período, pois mais da metade desenvolve suas atividades há dez anos. Cerca de um terço delas foi fundado a partir de 1991. Entre estas, 53,8\% no período entre 1991 e 1995 e as demais entre 1996 e 2001.

Em resumo, estas experiências mostram que organizar um cadastro qualificado das entidades da sociedade civil sem fins lucrativos foi e persiste sendo uma tarefa desafiadora, com grandes obstáculos, entretanto, perfeitamente factível, contrariando o freqüentemente enunciado. As principais dificuldades compreendem:

- obtenção dos diferentes cadastros pertencentes a diversas instituições, já que estes são percebidos pelas mesmas como uma espécie de fonte de poder;

- enorme quantidade e heterogeneidade dos cadastros parciais disponíveis: quanto à linguagem, aos critérios de seleção e à superposição ou duplicação de informações;

- organização e formatação das questões que compõem o questionário. Nesse sentido, o cadastro gerado ultrapassa em muito a simples coleta e agrupamento de cadastros já existentes, uma vez que envolve ampla tarefa de padronização, normatização e estruturação da linguagem para a fácil e rápida recuperação desses registros.

\section{Cadastro da Área Cultural e Esportiva na Região Metropolitana de São Paulo}

Trata-se de uma demanda da Secretaria de Cultura do Estado de São Paulo e o objetivo foi cadastrar e georreferenciar as entidades sem fins lucrativos que atuam na área de cultura, esporte e lazer na Região Metropolitana de São Paulo. Esta informação foi utilizada para subsidiar o projeto Fábricas de Cultura, realizado com o financiamento do BID e que pretende desenvolver equipamentos e ações culturais em áreas periféricas do Município de São Paulo, onde se concentram as áreas de maior índice de violência juvenil.

A base do cadastro foi novamente o Cadastro Central de Empresas - Cempre, organizado pelo IBGE, para 1999, com dados referentes a 1998. Através deste cadastro, chegou-se a uma relação de 1.743 entidades sem fins lucrativos, definidas segundo a natureza jurídica da empresa. Com a atualização realizada através do cadastro de 2000 , 
foram incorporadas 140 novas entidades. A seleção da área de atuação - esporte, cultura e lazer - foi definida segundo a atividade principal e baseou-se na Classificação Nacional de Atividades Econômicas - CNAE. Da combinação dos cadastros do Cempre 1998 e 1999 com a CNAE em cultura e esportes, chegou-se a um total de 2.287 entidades (1.743 do cadastro original; 146 novas entidades da atualização do cadastro Cempre/1999; 430 classificadas, por meio da CNAE, como "possíveis entidades com atuação em cultura e esportes"; excluindo-se 32 que haviam encerrado suas atividades, conforme apurado pela pesquisa "Cadastro de Entidades Sem Fins Lucrativos da Zona Leste"). Desse total, excluíram-se 344 entidades devido à falta ou erro de informação sobre o endereço, totalizando 1.943 entidades no cadastro. Dessas, foram realizadas, entre agosto e outubro de 2001, 1.129 entrevistas completas, 36 apenas o bloco cadastral e 802 não foram realizadas. Note-se que foram acrescidas 24 entidades que não faziam parte do cadastro original, mas foram localizadas nos endereços investigados e se enquadravam nos critérios do levantamento, perfazendo 1.967 instituições no universo pesquisado.

Com a distribuição espacial das entidades na Região Metropolitana de São Paulo, observaram-se, ao mesmo tempo, enorme concentração de equipamentos culturais e entidades que trabalham com cultura nas áreas centrais do Município de São Paulo e grandes "vazios" de entidades culturais no espaço da Região Metropolitana de São Paulo. Em seguida, buscou-se localizar novos equipamentos culturais junto à população jovem em uma das áreas periféricas em que há elevada incidência de violência: o Jardim Ângela, na Zona Sul do Município de São Paulo.

Considerou-se relevante mencionar a enumeração de pessoas que realizam trabalho voluntário - 75 mil na Zona Leste ( $1,9 \%$ da população local) e cerca de 8 mil em entidades culturais, esportivas e de lazer.

A importância da construção de um cadastro das entidades da sociedade civil, sem fins lucrativos, para a promoção da cultura, é ratificada pelo reconhecimento crescente da importante participação dessas entidades como parceiras ou protagonistas no desenvolvimento e inserção de atividades, programas e políticas das áreas social e cultural. Esse reconhecimento é um fenômeno mundial e vem sendo objeto de investigação de diversos organismos e instituições internacionais.

Deve-se ressaltar que se buscou ampliar a pesquisa para além da atualização de cadastro, disponibilizando informações abrangentes sobre o perfil e a forma de atua- ção destas entidades. Além dessa ampliação do escopo do trabalho, apresentam-se também as informações georreferenciadas, que proporcionam uma outra dimensão na análise dos resultados, uma vez que possibilitam localizar espaços de atuação das entidades culturais e identificar em que medida esses espaços de atuação na área cultural substituem, complementam ou se sobrepõem a ação governamental.

O padrão de atuação do Estado nessa área tem-se pautado não mais exclusivamente pela atuação direta, mas pelo incentivo às entidades não-governamentais (privadas com ou sem fins lucrativos) no estímulo às atividades culturais. As leis de incentivo nos âmbitos federal, estadual ou municipal são instrumentos que possibilitam efetivar a estratégia de descentralização e de fortalecimento da participação da sociedade civil na definição de ações na área cultural.

\section{Guia do Terceiro Setor}

Trata-se de um projeto que ambiciona disponibilizar na Internet, no formato georreferenciado, um conjunto significativo de entidades do Terceiro Setor que atuam no Estado de São Paulo. Este modelo de disseminação das informações possibilitará localizar no espaço das cidades as organizações cadastradas, além de caracterizá-las segundo um conjunto de informações básicas: nome, endereço, telefone, endereço eletrônico, natureza jurídica, data da fundação, atividade principal, existência de computador com acesso à Internet, número de funcionários e voluntários, ocorrência de parcerias com o setor público e privado, principal fonte de recursos e público-alvo. O projeto prevê ainda a atualização anual do cadastro.

O desenvolvimento de um instrumento de gestão de projetos sociais de tal envergadura e sua disponibilização na Internet certamente tornariam mais fácil e muito mais eficiente o esforço de responsabilidade social que vem ganhando força no Brasil e, de modo especial, em São Paulo. Particularmente beneficiados serão os organismos públicos, em geral, e as secretarias estaduais e municipais, em particular, que firmam parcerias com redes de entidades da sociedade civil, além de instituições do setor privado que desenvolvem ou pretendem desenvolver projetos sociais que incluam redes de Organizações NãoGovernamentais da sociedade civil.

Apesar da experiência acumulada nos trabalhos anteriores, e que sugeriam a importância do contato direto com a entidade a ser cadastrada, a metodologia para realizar o 
Guia do Terceiro Setor deverá seguir um outro caminho. O principal motivo desta correção de rumo é o acesso recente ao Cadastro da Receita Federal. De acordo com este cadastro, existem no Estado de São Paulo cerca de 130.000 entidades da sociedade civil sem fins lucrativos.

Destaca-se que o universo de pesquisa foi composto pelo Cadastro da Receita Federal (CNPJ - Cadastro Nacional de Pessoas Jurídicas da Receita Federal) e também pelos cadastros da Rais - Relação Anual de Informações Sociais, do Cempre - Cadastro Central de Empresas, do IBGE, cadastros de diferentes secretarias estaduais e municipais e até os vários cadastros das entidades e instituições públicas e privadas que atuam no Terceiro Setor. A Fundação Telefônica contribuiu com a doação de uma base de dados que associou aos CNPJs disponíveis cerca de $25 \%$ de números telefônicos, o que, infelizmente, é um percentual pouco expressivo, inviabilizando uma abordagem somente telefônica às entidades.

Essa unificação e consolidação possibilitou, ainda que em caráter preliminar, um conjunto bem interessante de resultados, como o já observado, de que estamos tratando de um universo com a magnitude de quase 130.000 entidades da sociedade civil, formalmente constituídas e instaladas no Estado de São Paulo. Dessas, quase 60\% estão dispersas no interior do Estado. Já a Região Metropolitana de São Paulo participa com mais de $40 \%$, ou seja, aproximadamente 60 mil entidades. O Município de São Paulo destaca-se no abrigamento de mais de 40 mil instituições sem fins lucrativos, em 2002. Desse total, cerca de $70 \%$ correspondem a organizações religiosas, entidades desportivas e outras associações.

Essas informações serão objeto de inúmeras checagens e consistências. Adicionalmente, o Guia do Terceiro Setor pretende desvelar alguns dos tantos aspectos, tais como: questionamentos sobre as respectivas áreas de atuação; segmentos sociais que costumam atender; fontes de financiamento; relações de parcerias; etc.

Desse modo, em função da magnitude do universo pesquisado e dos altos custos que decorreriam de uma investigação em campo (à propósito do que ocorreu com os projetos Sebrae e Secretaria de Estado da Cultura) com o contato direto dos pesquisadores junto aos representantes das associações, a Fundação Seade e parceiros decidiram por um novo conjunto de procedimentos para coleta de informações:

- disponibilização, no site do Seade e da Fundação Mário Covas, de informações oriundas do atual cadastro unificado e sistematizado pela Fundação Seade e, concomi- tantemente, apresentação de um formulário eletrônico que poderá ser acessado pelas instituições por meio de uma senha (CNPJ), para que as mesmas, mediante seu representante legal, confirmem seus dados cadastrais e respondam a resposta a uma pesquisa de qualificação dos dados da instituição. Obviamente, procedimentos específicos serão utilizados para tratar com as novas instituições (não constantes do cadastro inicial) que acessem os sites, de modo a incluí-las e qualificá-las;

- desenvolvimento de uma estratégia de divulgação e marketing junto aos mais relevantes agentes relacionados ao Terceiro Setor, desde rádios comunitárias, jornais regionais e de bairro, até prefeitos dos municípios paulistas, redes como RITS - Rede de Informação do Terceiro Setor, Setor 3 do Senac, Abong - Associação Brasileira de ONGS, Conselho Regional dos Contabilistas, Fundação Telefônica, Instituto Ethos, entre outros. Nossos esforços serão no sentido de tê-los como agentes de divulgação e parceiros estratégicos na construção do Guia, com contribuições que poderão traduzir-se na cessão de voluntários para ações específicas, investimento de recursos financeiros ou intercâmbio de expertises;

- aplicação de um sistema de controle e consistência dos dados coletados pela Internet, por intermédio de uma equipe de telepesquisa, especialmente treinada para contatos telefônicos e checagem da veracidade das informações obtidas remotamente;

- retroalimentação do site do Seade e da Fundação Mário Covas com os dados cadastrais e de qualificação das entidades, num processo cumulativo e de aperfeiçoamento permanente do Guia do Terceiro Setor.

\section{CONSIDERAÇÕES FINAIS}

Percebemos que serão muitas as dificuldades, desde compor parcerias eficazes e sensibilizar dirigentes do setor sobre a importância e fidedignidade das informações relativas às suas entidades, até desenvolver e aperfeiçoar instrumentos eletrônicos de coleta de dados, solucionar problemas metodológicos conceituais (como, por exemplo, decidir sobre a melhor forma de classificar as atividades desenvolvidas pelas entidades), oferecer treinamento especializado em pesquisa telefônica e analisar, especialmente de forma criteriosa, os aspectos relevantes para divulgação.

Entretanto, como comprova a trajetória que a Fundação Seade escolheu fazer desde a primeira vez em que foi 
solicitada a produzir informações estatísticas sobre o Terceiro Setor, não faltarão empenho, flexibilidade e criatividade para alcance desse objetivo.

O desenvolvimento de um instrumento de gestão de projetos sociais de tal envergadura e sua disponibilização na Internet certamente tornarão mais fácil e muito mais eficiente o esforço de responsabilidade social que vem ganhando força no Brasil e, de modo especial, em São Paulo.

Particularmente beneficiados serão os organismos públicos, em geral, e as secretarias estaduais e municipais, em particular, que firmam parcerias com redes de entidades da sociedade civil, além de instituições do setor privado que desenvolvem ou pretendem desenvolver projetos sociais que incluam redes de organizações não-governamentais da sociedade civil.

O propósito é que ao longo do tempo, ao se cristalizar uma metodologia de captação e organização de dados do Terceiro Setor, especialmente aquela parcela que envolve as pequenas entidades comunitárias, a Fundação Seade e seus parceiros venham a se tornar, via Internet, centros de referência para coleta e consultas mais detalhadas de informações relativas ao Terceiro Setor, sobretudo aquele de perfil mais comunitário.

Portanto, essa contribuição será decisiva ao fortalecimento do Terceiro Setor para a evolução e o aperfeiçoamento da implementação de políticas compensatórias, visando as populações mais necessitadas, e para a ma- croeconomia, uma vez que permitirá o conhecimento das estatísticas reais de um importante segmento da atividade econômica, geração de emprego e cidadania.

O legado mais importante da realização deste trabalho, contudo, talvez seja o de instalar a transparência das ações realizadas em parcerias com o setor público. De fato, uma vez instalado o Guia do Terceiro Setor na Internet, problemas graves e freqüentes, como o desconhecimento do desempenho da entidade para a qual se está repassando verba, das fontes de financiamentos a que ela teve acesso, da sua capacidade de gerenciamento dos mesmos e da sua inserção na comunidade do entorno, poderão ser naturalmente minimizados.

\section{REFERÊNCIAS BIBLIOGRÁFICAS}

BNDES. Terceiro Setor e desenvolvimento social. Brasília: jul. 2001. (Relato setorial, n.3).

FERNANDES, R.C. Privado porém público - o Terceiro Setor na América Latina. Rio de Janeiro: Relume Dumará, 1994.

SALAMON, L.M.; HELMUT, K.A. The emerging nonprofit sector an overview. Manchester, UK: Manchester University Press, 1996.

Felícia Reicher Madeira: Socióloga, Demógrafa, Diretora Executiva da Fundação Seade (fmadeira@seade.gov.br).

Miriam Ribeiro Biancardi: Economista, Analista da Fundação Seade (mribeiro@seade.gov.br). 